CLINICAL CASE

\title{
MINIMALLY INVASIVE ESOPHAGECTOMY THROUGH MODIFIED MCKEOWN TRIPLE APPROACH WITH ESOPHAGEAL RECONSTRUCTION AND GASTRIC PULL-UP FOR THORACIC ESOPHAGEAL CARCINOMA
}

\author{
Angelica Nicoleta Ionescu ${ }^{1}$, Cristina Ghiță ${ }^{1}$, Andreea Maria Stoean ${ }^{1}$, I.F. Achim ${ }^{2}$, \\ A. Constantin ${ }^{2}$, Adriana Ghelmene ${ }^{2}$, M. Gheorghe ${ }^{2}$, Adelina Birceanu ${ }^{3}$, S. Constantinoiu ${ }^{2}$ \\ ${ }^{1}$ The University of Medicine and Pharmacy "Carol Davila", Bucharest, Romania \\ ${ }^{2}$ Center of Excellence in Esophageal Surgery, Clinical Hospital "Saint Mary", Bucharest, Romania \\ ${ }^{3}$ Patology Department, Clinical Hospital "Saint Mary”, Bucharest, Romania \\ Corresponding author: Ion-Florin Achim \\ Phone no. 0040727114477 \\ E-mail: achim.florin@yahoo.com
}

\begin{abstract}
We present the technique of triple approach minimally invasive subtotal esophagectomy: thoracoscopy, laparoscopy and left cervicotomy with gastric pull-up and cervical esogastric anastomosis in a 59 y.o patient. He was diagnosed with a middle thoracic esophageal tumor. The histologic report, thoracic CT and echoendoscopy confirmed the presence of scuamos esophageal carcinoma.
\end{abstract}

Keywords: minimally invasive esophagectomy, esophageal cancer

\section{Introduction}

Traditional esophagectomy is associated with mortality, considerable morbidity, and long recovery. It is often performed in old cancer patients, have associated comorbidities, and are malnourished, all factors that increase surgical risks. Minimally invasive esophagectomy (MIE) has the advantages of a less traumatic procedure with an easier postoperative recovery and fewer wound and pulmonary complications[1]. MIE has gained popularity over the past twenty years. The objective is to decrease the high overall morbidity of a traditional open esophageal resection. The whole spectrum of open esophagectomy techniques has been replicated in a minimally invasive variant [2]. Although minimally invasive surgical approaches to esophagectomy have been introduced since 1992, MIE is still considered investigational at most institutions[3].

\section{Case presentation}

A 59 years old patient presented with disfagia for solid food in the last 4 months. The patient had been known with essential hypertension for 10 years, goiter, acute duodenitis and gastritis in the past medical history. The clinical examination showed no abnormalities. 


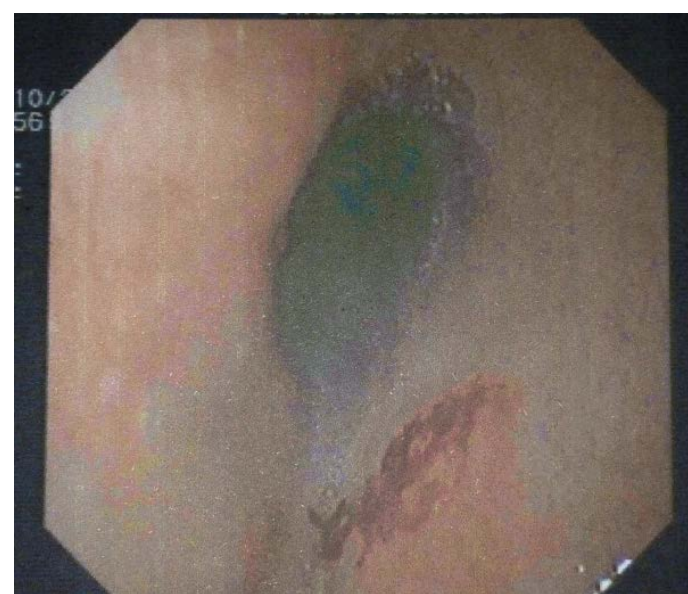

Figure 1 - GDE

The last endoscopy showed the presence of a flat erosive lesion (aproximatively $2 \times 2 \mathrm{~cm}$ ), located 29 centimeters far from the dental arcade with irregular surface and margins scuamos intraepitelial esophageal carcinoma with severe displasia.

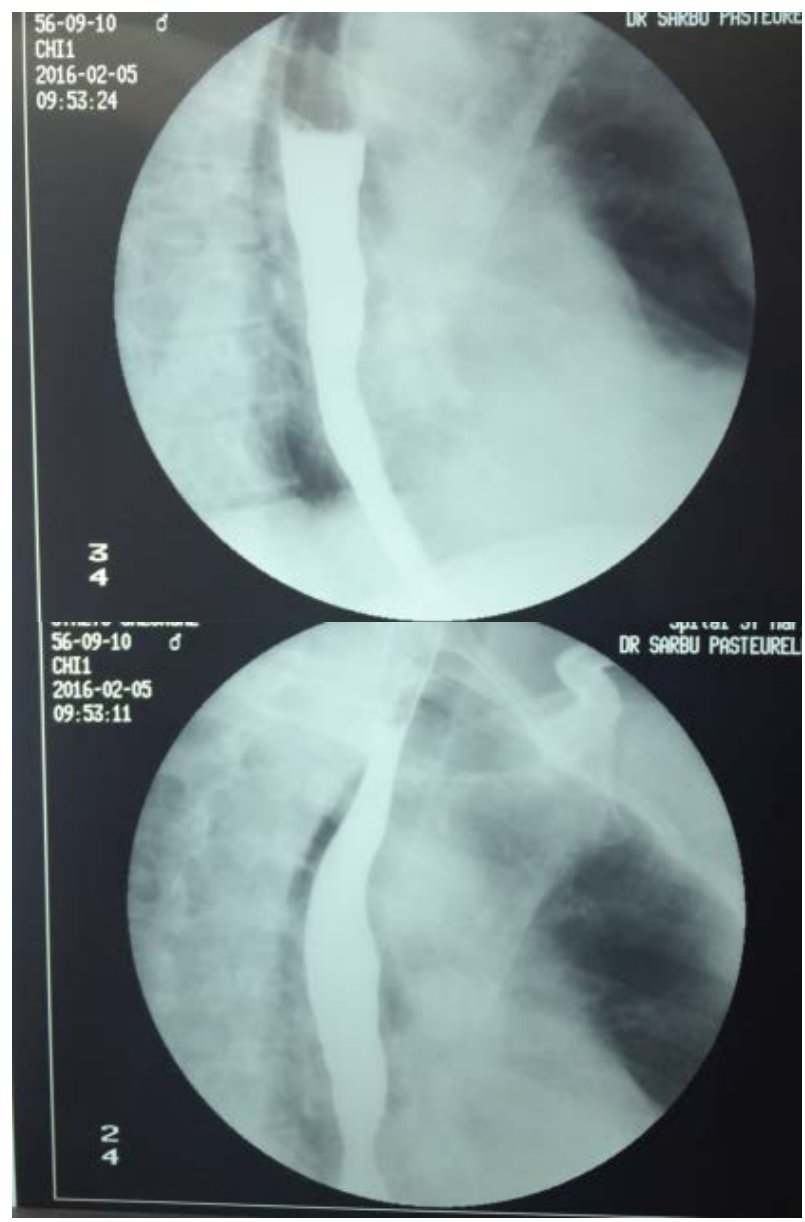

Figure 2 - Barium passage

The patient was investigated barium passage, endoscopy, ecoendoscopy and CT thorax which confirmed the presence of scuamos esophageal carcinoma stage IB cT1N0Mx. The ecoendoscopy examination showed invasion only in the mucosa and submucosa, with no locoregional adenopaties.

Decrease in motility with hypertonic dyskinesia in the lower half of the esophagus. The stomach motility was not affected with a slight stasis in the first part of duodenum. Moderate gastroesophageal reflux.

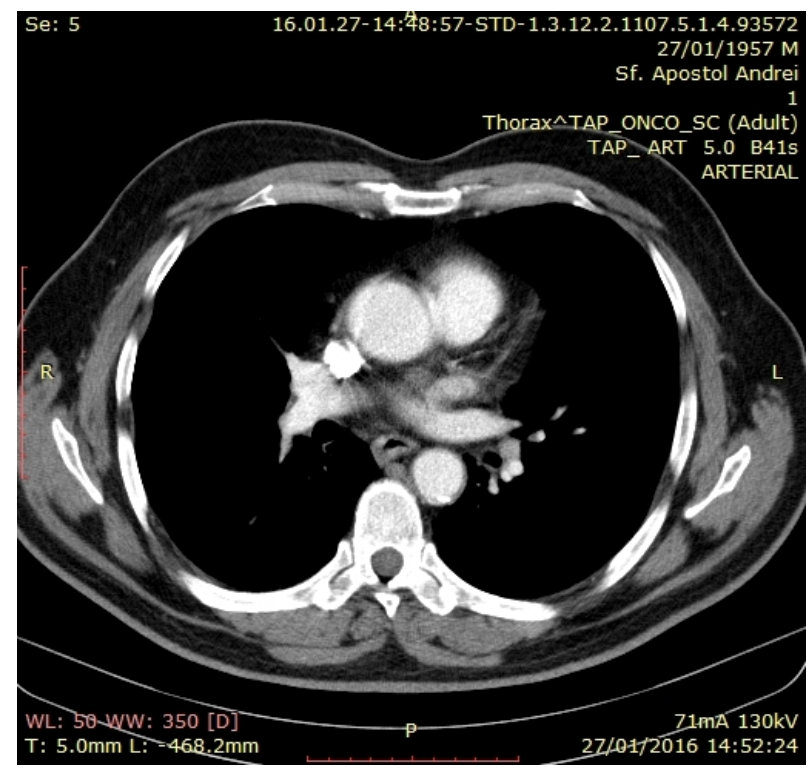

Figure 3 - CT Thorax- Axial view

Discrete thoracic esophageal expansion in the upper third, with rare basal subpleural nodules located bilaterally.

The patient was discussed in a multidisciplinary meeting and esofagectomy was indicated. From the oncological point of view patients with T1-2N0 esophageal cancer typically are recommended to undergo surgery without induction treatment. We considered minimally invasive approach(MIE) suitable for this case. Pre anaesthetic assessment included: subcutaneous LMWH (low molecular weight heparin) administration, incentive spirometry and mechanical bowel preparation.

A subtotal minimally invasive esophagectomy under general anaesthesia( OP no $183 / 18.02 .2016)$ was performed, using the modified McKeown technique (thoracoscopic, laparoscopic and left cervicotomy) with gastric pull-up (Nakayama technique), cervical esogastric anastomosis and feeding jejunostomy.

\section{Thoracoscopic stage}

For the thoracoscopic stage, is used left selective orotracheal intubation with a Carlens 
endotracheal tube and the patient was positioned in left lateral decubitus position.

Main surgeon is situated on the right and the assistent and the cameraman on the left side of the patient. There are 5 thoracic ports used as following:

- $10 \mathrm{~mm}$ port camera (45 degree $10 \mathrm{~mm}$ camera) at the 8th intercostal space anterior to midaxillary line

- $10 \mathrm{~mm}$ port at the 9th intercostal space, posterior to posterior axillary line

- $10 \mathrm{~mm}$ port at the 7th intercostal space, in the anterior axillary line,

- $10 \mathrm{~mm}$ port at the 4th intercostal space, in the anterior axillary line, in order to pass a fan shaped retractor to retract the lung anteriorly and allow exposure of the esophagus

- $5 \mathrm{~mm}$ port anterior to the scapula tip, used for placing instruments for retraction and countertraction.

We insuflated the right chest with $\mathrm{CO} 2$ at pressure of $8 \mathrm{mmHg}$ which helped to colapse the right lung.

The right lung was retracted using a $10 \mathrm{~mm}$ Fan Endorectractor for better visualisation of the thoracic esophagus, and the inferior pulmonary ligament is sectioned at the level of the inferior pulmonary vein. The mediastinal pleura overlying the esophagus is divided up to the azygos vein, and the entire thoracic esopagus is exposed and there is no invasion outside the adventicia and no periesophageal adenopaties. When disecting at the point of subcarinal nodes, attention must be paid so as not to injure the mainstern bronchi. Using the stapler (EndoGia Ultra) the azygos vein is then divided. In order to facilitate traction and exposure of the thoracic esophagus, a traction tube is placed around the esophagus. Dissection of the esophagus with all its surrounding lymph nodes, periesophageal tissue is performed from the diaphragm to the upper thorax. Large endoclips and Ligasure are used for lymphatics and aortoesophageal vessels posteriorly to reduce bleeding and chylothorax complications.

After the esophagus has been mobilised, two drainage tubes connected to Beclaire aspiration system must be put into place: one at the base and one at the apex of the lung which is expanded at the end of this stage of operation.

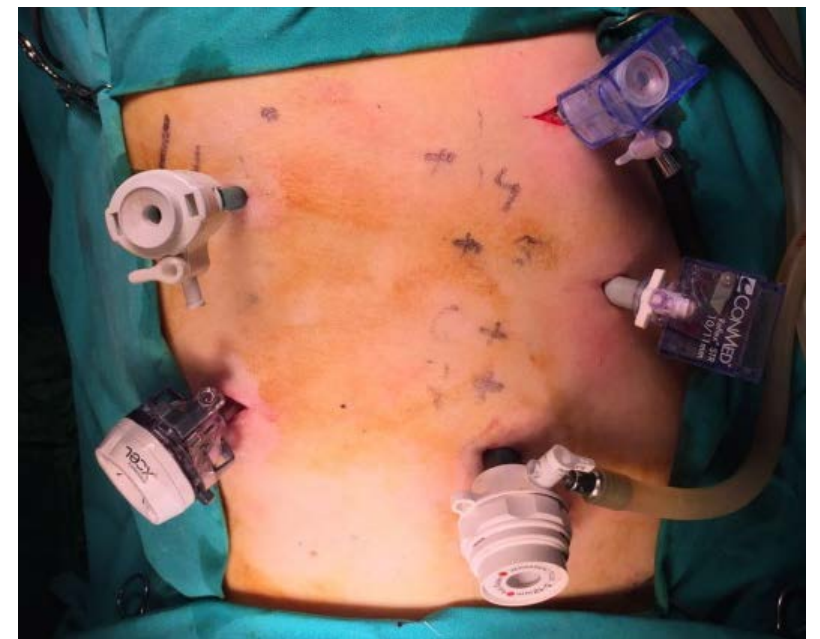

Figure 4 - Thoracic trocars placement

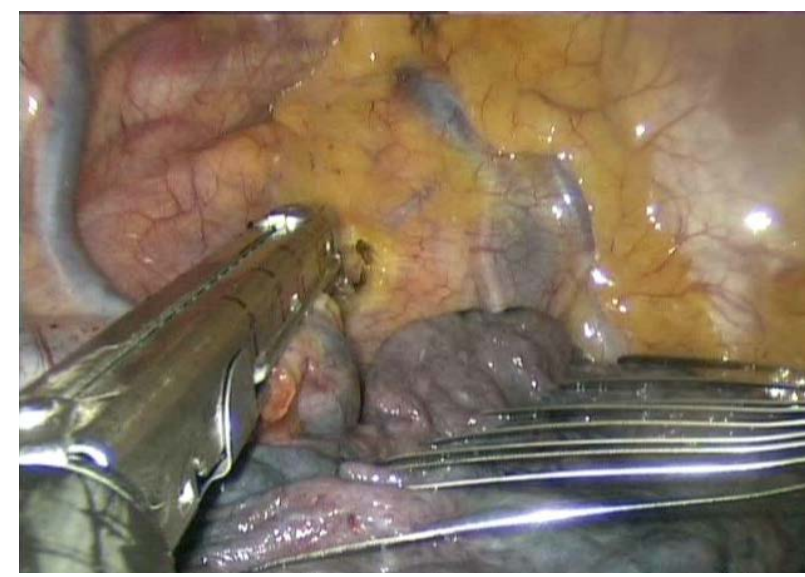

Figure 5 - Section of azygos vein

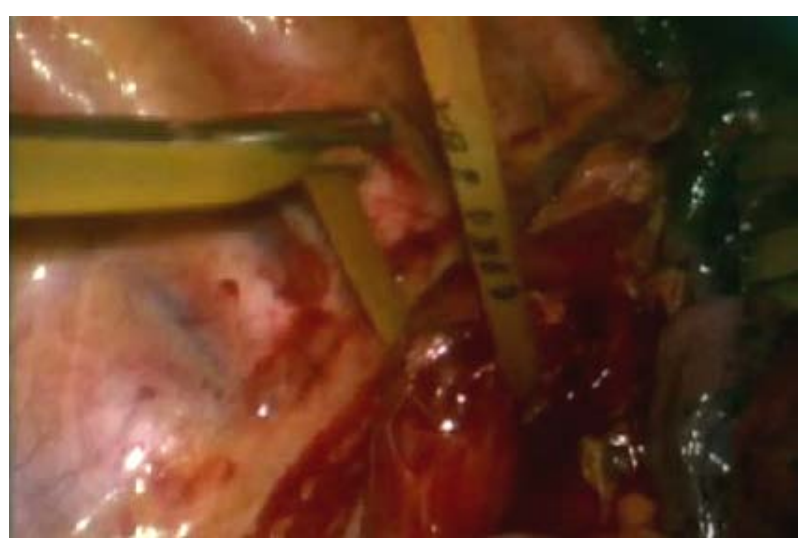

Figure 6 - Disection of the esophagus

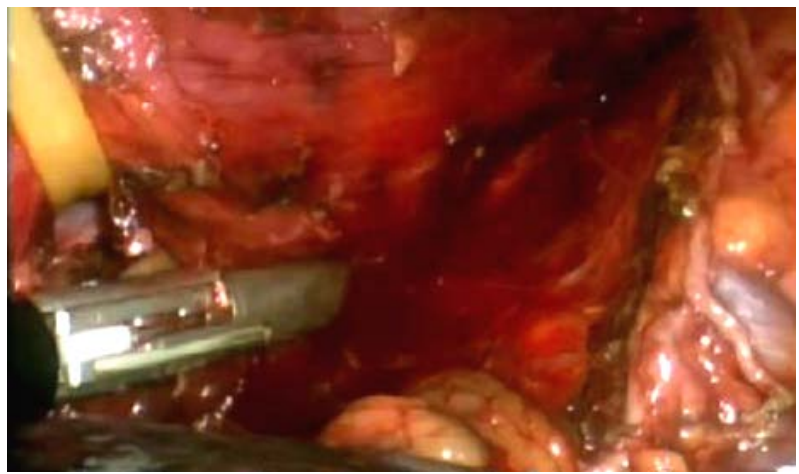

Figure 7 - Disection of the esophagus 


\section{Abdominal laparoscopic stage}

The patient is positioned in supine position for the gastric mobilisation. Afterwards, the double lumen tube (ETT) is replaced with a single lumen tube and 5 abdominal ports are placed on the anterior abdominal wall.

- $10 \mathrm{~mm}$ camera port (45 degree) $10 \mathrm{~mm}$ supraumbilical

- $10 \mathrm{~mm}$ port subxifoidian, fan shaped retractor to retract the liver to the right and allow exposure of the esophageal gastric junction;

- $10 \mathrm{~mm}$ port right to the middle clavicular line, supraumbilically

- $10 \mathrm{~mm}$ port left the middle clavicular line, supraumbilically

- $5 \mathrm{~mm}$ port in the left flank used for placing instruments for retraction and countertraction.

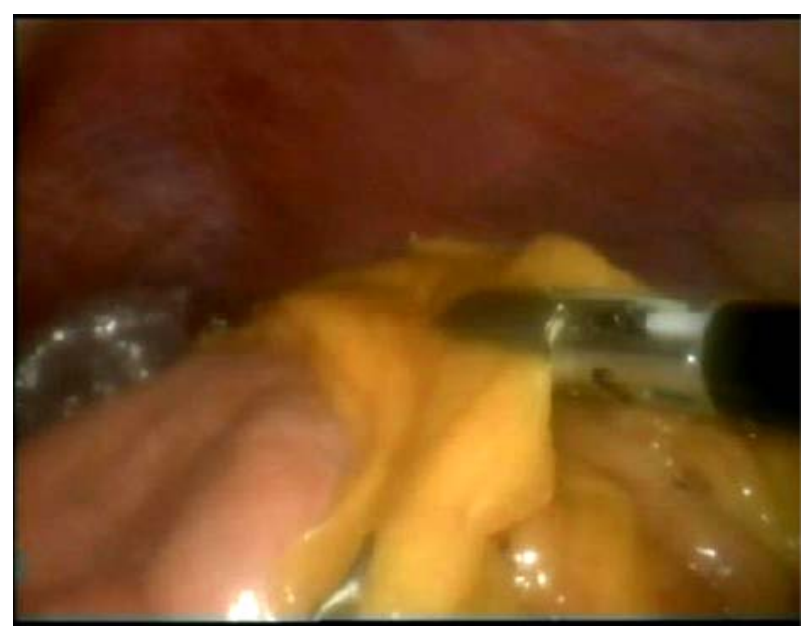

Figure 8 - Section of gastrocolic ligament

In order to expose the esophageal hiatus the left hepatic lobe is retracted using a $10 \mathrm{~mm}$ Fan Endorectractor. Placing the patient in maximal Fowler position, the dissection begins by dividing the gastrocolic ligament from the middle, continuing with the dissection of the gastrofrenic and gastrosplenic ligaments. Using Ligasure and large endoclips, the short gastric vessels are ligated, to avoid potential displacement during gastric pull-up, no clips were placed. The dissection continues on the large curvature of the stomach preserving the right gastro-epiploic arcade. Dissection of lymph nodes of the celiac and gastric vessels is facilitated by retracting the stomach superiorly. Once the left gastric artery and vein are exposed, the vascular stapler is used to divide them. The abdominal esophagus and the right diaphragmatic crus are dissected using Ligasure.

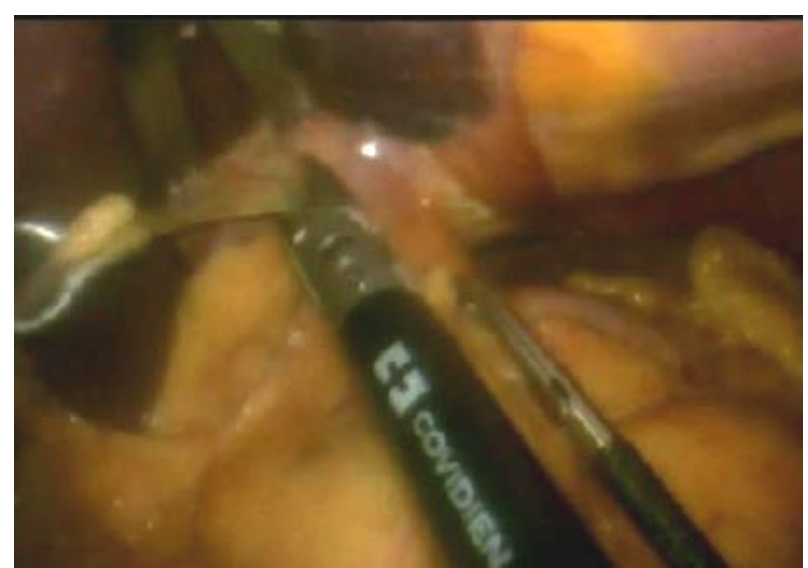

Figure 9 - Intraoperative section of the hiatus

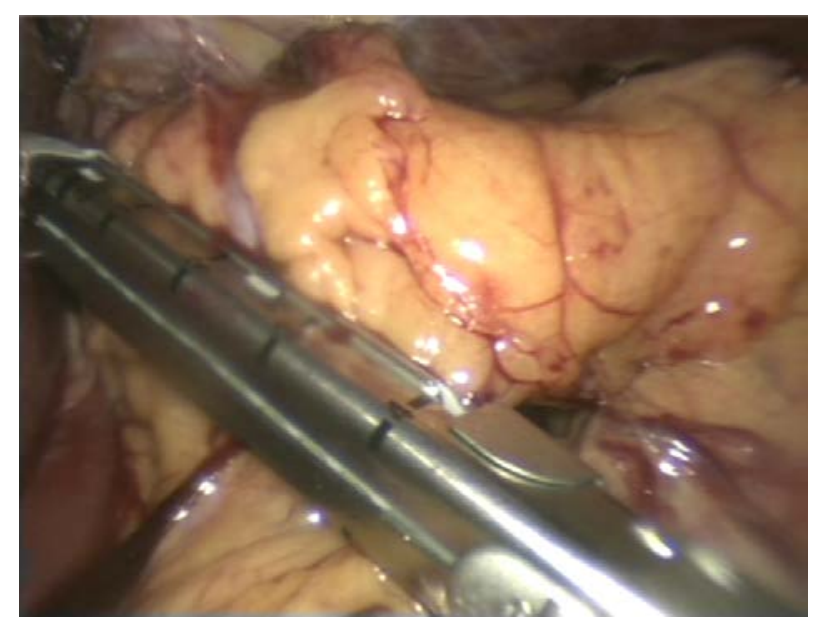

Figure 10 - Section of left gastric artery

\section{Cervical stage}

For the left lateral cervicotomy a $4-6 \mathrm{~cm}$ is performed, to the left of the midline above the suprasternal notch, at the medial margin of the sternocleidomastoidian muscle, prevascular and above the prevertebral fascia. The cervical esophagus is then mobilised, dissected and sectioned above jugular incisure of the sternum. The distal end of the esophagus is closed and attached to a traction tube(Levine nasogastric tube).

A minimal supraombilical laparotomy is performed in order to extract the surgical specimen, prepare the gastric conduit and perform a jejunostomy. The esophageal specimen is retrieved.

The stomach is prepared following the Nakayama technique, using a linear stapler to section the cardia, the mechanical suture being enforced by a surjet manual suture. Pyloroplasty was considered not necessary for this case. 


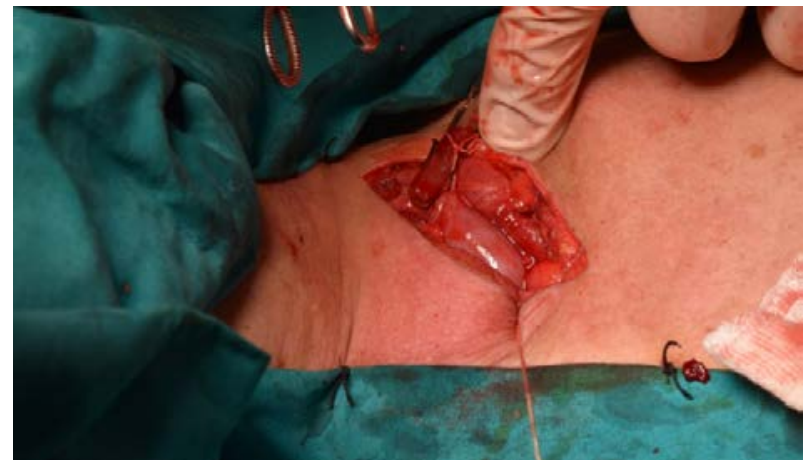

Figure 11 - Intraoperative picture - left lateral cervicotomy

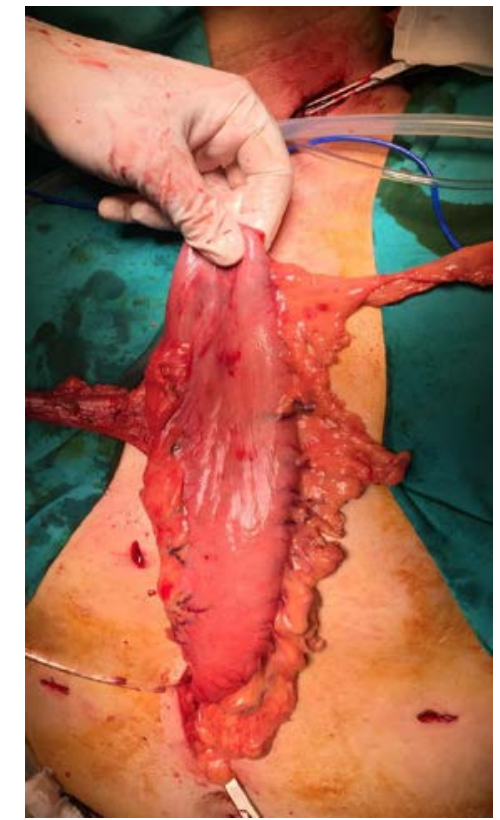

Figure 12 - Intraoperative picture - preparing the gastric conduit

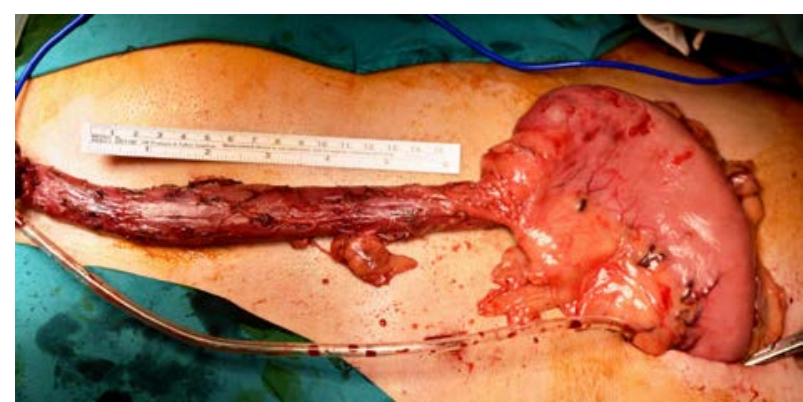

Figure 13 - Intraoperative picture - preparing the gastric conduit

The gastric conduit is attached to the traction tube and pulled-up through the posterior mediastinum and anastomosed end-to-side with the cervical esophagus using a single layer 4.0 surjet suture. The cervical incision is closed with simple Silk 4.0 discontinuos sutures.

A jejunostomy that opens into the left hypochondrium is put into place using a 20ch Foley tube attached to the parietal peritoneum using 3.0 Silk stiches. Drainage tubes for the peritoneal cavity are positioned.

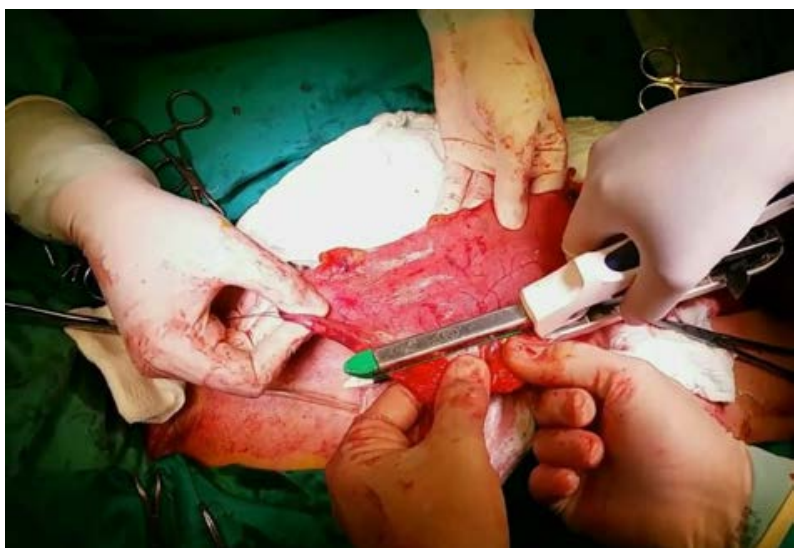

\section{Figure 14 - Section the cardia}

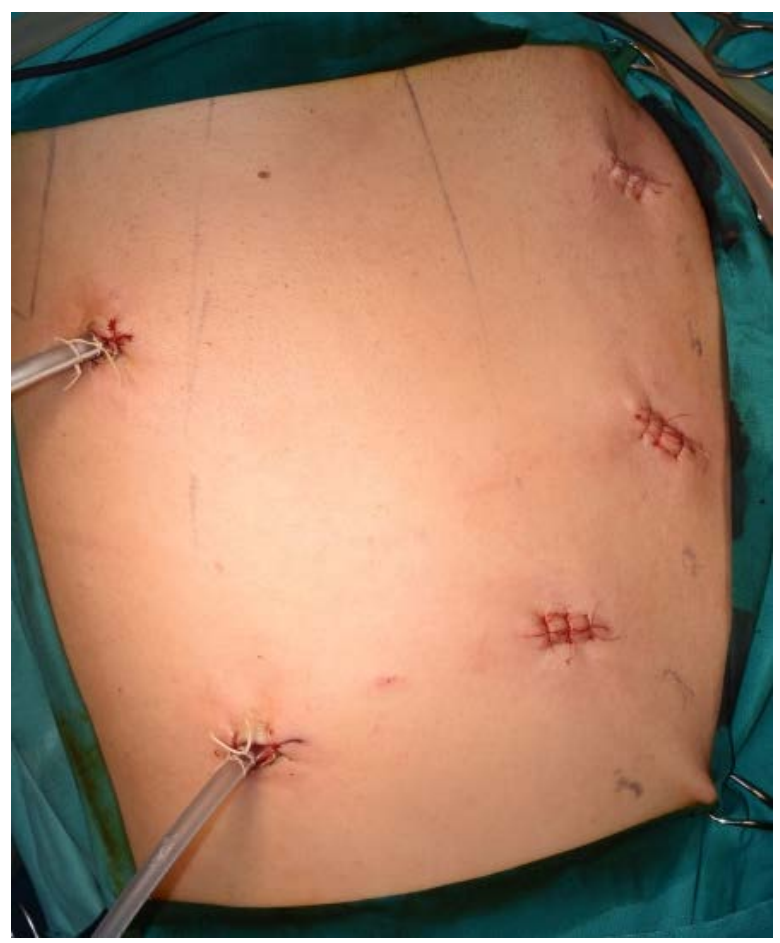

Figure 15 - Postoperative picture

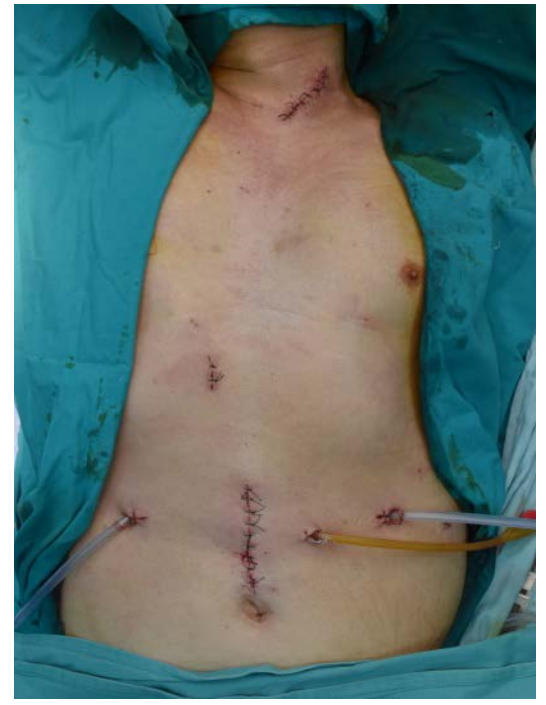

Figure 16 - Postoperative picture 


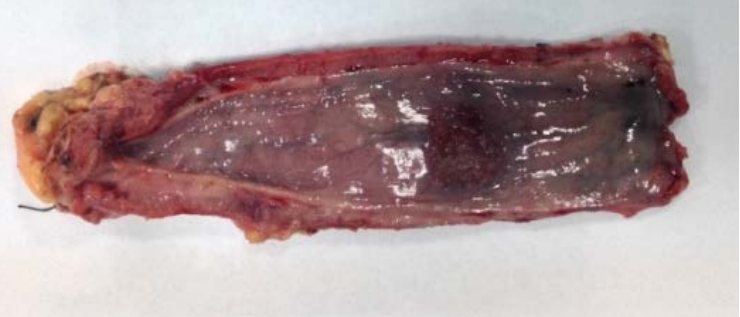

Figure 17 - Tumorectomy specimen

Postoperative $\mathrm{x}$-ray showed pneumothorax with subcutaneous emphysema on the right hemithorax which was treated conservatively. Evolution was favourable with earlier mobilisation, no other surgical complications, enteral feeding was commenced in the 2nd postoperative day through jejunostomy( Nutren $20 \mathrm{ml} / \mathrm{h}$ ). Patient had a short stay in the ICU and patient required less dosage of analgetic opiods after removing the epidural catheter .

In the 7th postoperative day a contrast x-ray study was done which showed no anastomotic fistula and delayed gastric emptying. Oral feeding was started and was well tolerated and the pleural drainage was removed. The patient was discharged in the 13th postoperative day after 19 days hospital stay with recommendation for oncological reevaluation in order to establish further course of treatment.

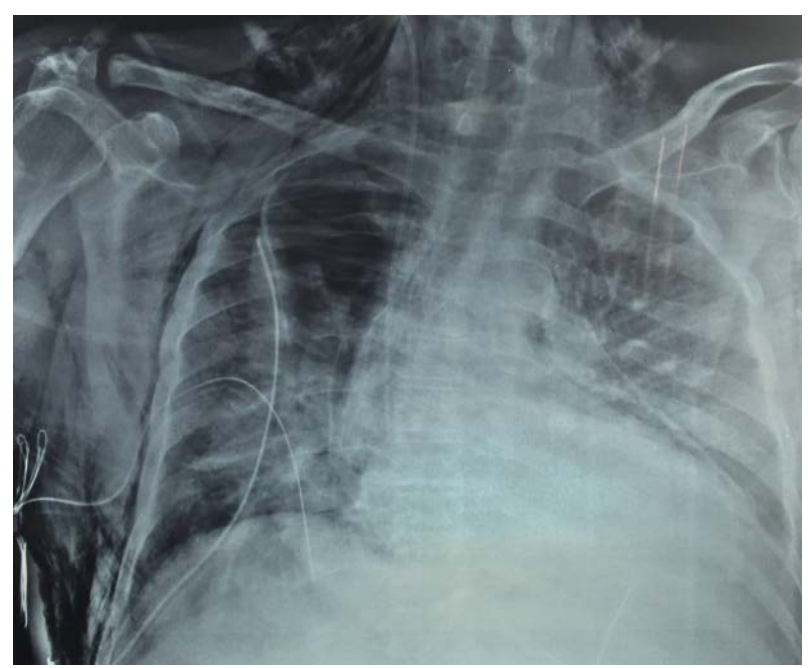

Figure 18 - Postoperative pneumothorax with subcutaneous emphysema

The stomach is pulled-up in the thorax, on the right paravertebral side and air fluid level in the gastric conduit. There is no radiologic sign of fistulas.

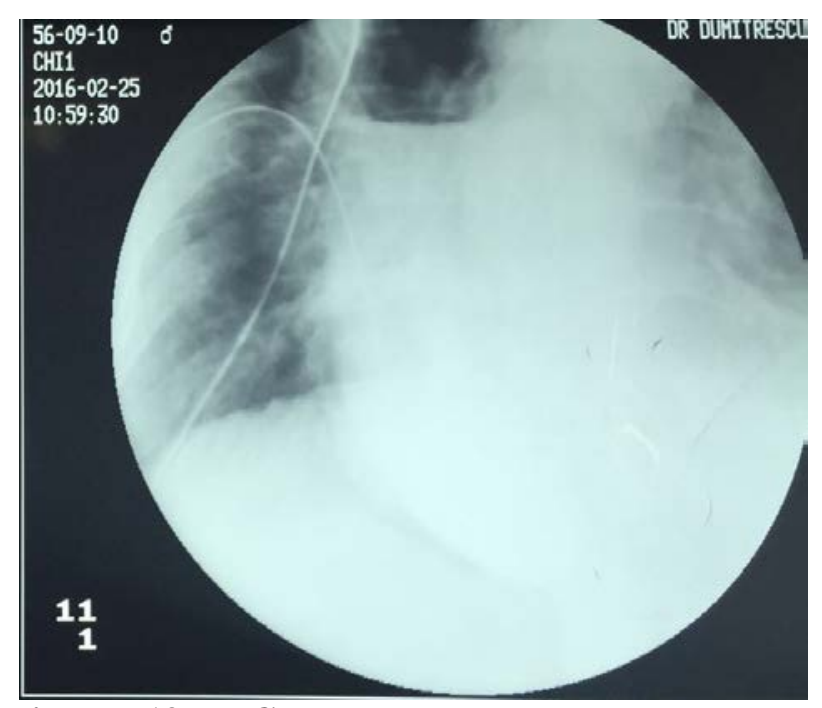

Figure 19 - Contrast study control 7th day postoperatively

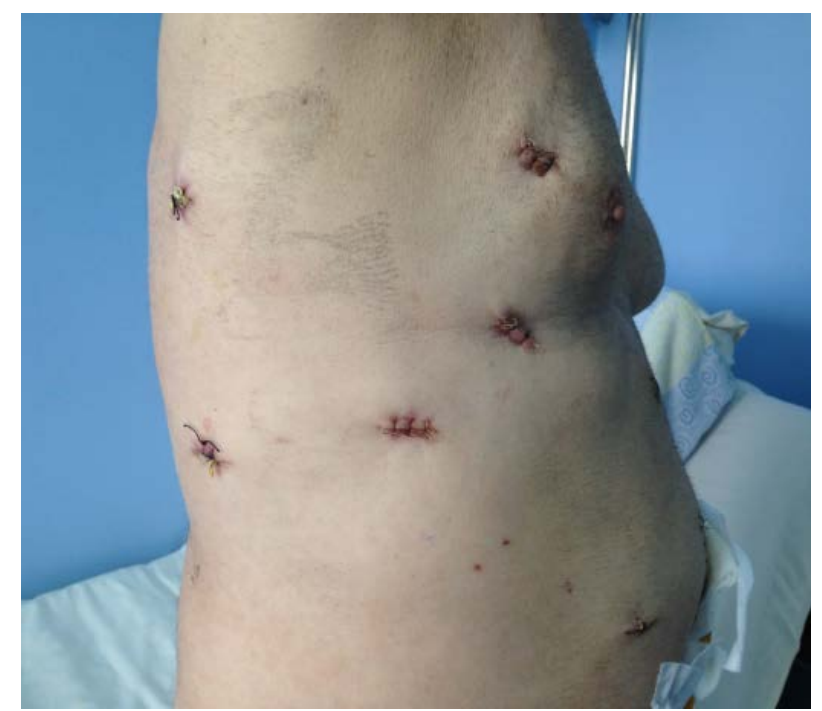

Figure 20 - postoperative picture

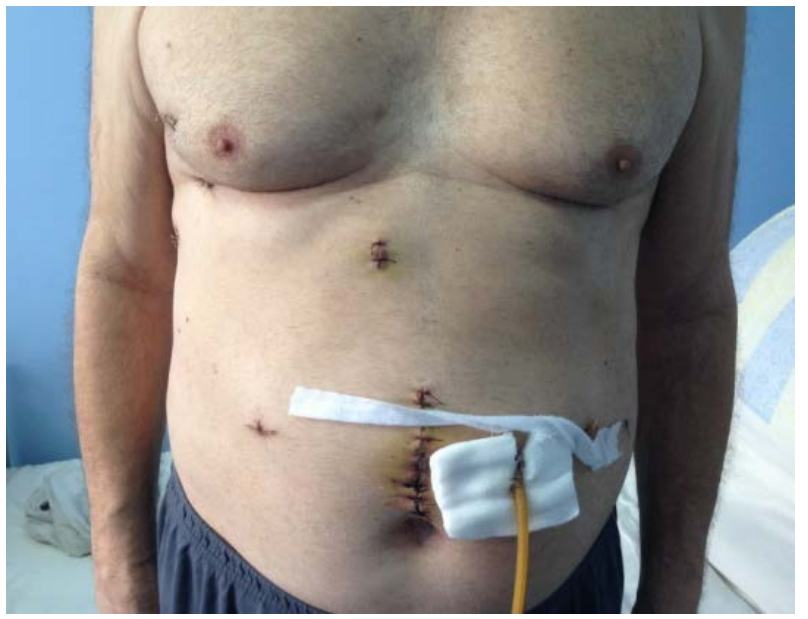

Figure 21 - postoperative picture

The final histological report confirmed the presence of scuamos esophageal carcinoma stage II pT1N0M0. 


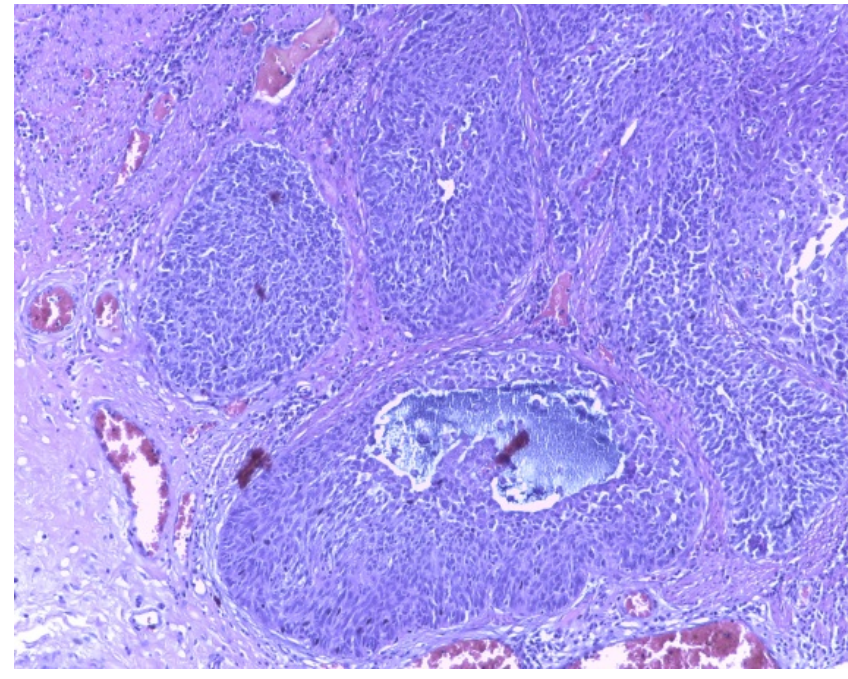

Figure 22 - HE 10X

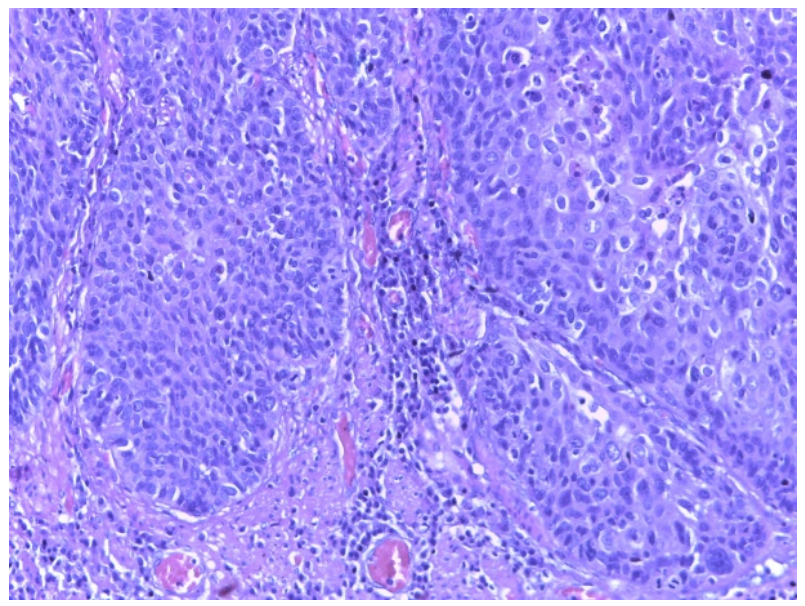

Figure 23 - HE 10X

Esophageal mucosa fragments with unkeratinised, pluristratified, scuamos epithelium aspect showing signs of malignant proliferation among muscular fibers. The cells are medium sized with abundant cytoplasm, slightly eosinophilic, hypertrophic nucleii with 1-2 nucleoli. In addition to these, we noticed groups of tumoral poligonal cells with clear, light-eosinophilic cytoplasm with frequent mytosis, some of them abnormal. Rarely, apoptotic bodies could be noticed.

The patient underwent oncological evaluation and the adjuvant treatment was recommended. The jejunostomy tube was removed after the surgery, the patient is alive, free from recurrence 3 months after surgery and is due for 6 months follow up.

\section{Discussion}

Esophagectomy remains the mainstay of treatment in patients with potentially resectable esophageal cancer. The surgical trauma imposed by esophagectomy is perhaps the greatest amongst the standard general surgical procedures, often involving simultaneous exploration of the abdomen, chest and neck. Minimally invasive esophagectomy (MIE) was introduced in the 1990s in an effort to reduce the morbidity and mortality associated with the traditional open surgical approach. Since then, there has been several studies that have documented the advantages of the minimally invasive approach over the standard transthoracic and transhiatal esophagectomy. These include comparable operative time, decreased blood loss, decreased pulmonary complications, less vocal cord palsy, and reduced intensive care and hospital stay $[4,5,6$, $7,8]$. Also the advantages of MIE include a magnified view of the operative field. This advantages theoretically enhances the ability to perform more radical lymphadenectomy, in contrast surgeons must be less confident to work close to important vascular structures without a tactile feeling and the possibility to use their hands to control bleeding. It have been shown that esophagectomy outcomes are highly linked to the experience of the centers performing the operation, the surgeons experience in minimally invasive surgery, thoracoscopic and laparoscopic and also an experienced intensive care.

Regarding the surgical approach studies have shown similar results in the lymph node resection, postoperative morbidity and mortality rate in both open esophagectomy (OE) and minimally invasive esophagectomy (MIE). In experienced hands, MIE could be an attractive approach for patients with conditions requiring esophageal resection and for early cancers. There are various technical option for MIE such as total laparoscopic/ thoracoscopic transhiatal esophagectomy (THE) or tripple approach also hybrid procedures with at least one of the approaches being done via laparoscopy/thoracoscopy [9, 10].

In our surgical department open technique was used with good outcomes and we decided to introduce MIE because it has less pulmonary 
complications. Left lateral decubitus position (LDP) was used despite prone position (PP), in case of a vascular complication may appear during surgery, this position allows an emergency thoracotomy to be performed. The primary benefit of the prone position is derived from the anatomical exposure of the esophagus the surgeon gets in this position. The lung falls down because of the effect of gravity and the esophagus is well visualized. This enables performance of the operation without collapsing the right lung completely using a double-lumen endotracheal tube. In the lateral position, the esophagus is in a dependent position and any pooling of blood obscures the surgical field, whereas in the prone position, the blood pools away from the operative field [11]. A French position was used for the abdominal laparoscopic stage in this case, because is an efficient position, the surgeon with experience in esophageal gastric junction pathology using laparoscopic techniques has a better view of the operative field and good access for the rest of the surgical team. The stomach is the most commonly used esophageal substitute after esophagectomy. In case the location of the tumor is in the middle or upper esophagus- the whole stomach with resection of cardia can be used-Nakayama technique. If lower esophageal tumor is present the gastric conduit is prepared with resection of lesser curvature -Akiyama technique. The utility of prophilactic pyloroplasty or pyloromyotomy to prevent delayed gastric emptying after esophagectomy with esophageal reconstruction is controversial and is not routinely indicated [12].

If MIE cannot demonstrated to be less invasive, some studies at least suggest that postoperative ventilation times, blood loss, transfusion rates, length of ICU and hospital stay could be favorably influenced by MIE [13, $14,15,16,17]$. The quality of life is increasingly becoming an important outcome assessment for patients who have undergone esophagectomy. A comparative analysis of outcomes after open versus MIE was performed and overall results conclude that there was no significant difference in any of the quality of life parameters between open versus MIE [9, $11]$. 
Oesophago-Gastric (SC3-OG) A prospective comparison of totally minimally invasive versus open Ivor Lewis esophagectomy. Dis Esophagus. 2013;26:263-71. [PubMed]

[7]Biere SS, van Berge Henegouwen MI, Maas KW, Bonavina L, Rosman C, Garcia JR, et al. Minimally invasive versus open oesophagectomy for patients with oesophageal cancer: A multicentre, open-label, randomised controlled trial. Lancet. 2012;379:1887-92. [PubMed]

[8] Amit Javed, John Mathew Manipadam, Amit Jain, R. Kalayarasan, Rajeev Uppal, and Anil K. Agarwal-Minimally invasive oesophagectomy in prone versus lateral decubitus position: A comparative study J Minim Access Surg. 2016 JanMar; 12(1): 10-15

[9] Review of Minimally Invasive Esophagectomy and Current Controversies T. Kim, S. N. Hochwald, G. A. Sarosi, A. M. Caban, G. Rossidis, and K. Ben-David Gastroenterology Research and Practice Volume 2012 (2012), Article ID 683213

[10] F. A. Herbella and M. G. Patti, "Minimally invasive esophagectomy," World Journal of Gastroenterology, vol. 16, no. 30, pp.3811-3815, 2010.

[11] A. Sundaram, J. C. Geronimo, B. L. Willer et al., "Survival and quality of life after minimally invasive esophagectomy: a single-surgeon experience," Surgical Endoscopy and other Interventional Techniques, vol. 26, no. 1, pp. 168176, 2012.

[12] Rescue pyloroplasty for refractory delayed gastric emptying following esophagectomy Jashodeep Datta, MD, Noel N. Williams, MB, BCh, MCh, R. Gregory Conway, BSME, Daniel T. Dempsey, MD, MBA, and Jon B. Morris, MD, Philadelphia, PA

[13] Bonavina L, Bona D, Binyom PR, Peracchia A. A laparoscopy-assisted approach to esophageal carcinoma. J Surg Res 2004;117:52-7.

[14] AkaishiT, Kaneda I,HiguchiN, KuriyaY, KuramotoJ, ToyodaT, Wakabayashi A. Thoracoscopic en bloc total esophagectomy with radical mediastinal lymph-adenectomy. J Thorac Cardiovasc Surg 1996;112:1533—41.

[15] Swanstrom LL. Minimally invasive surgical approaches to esophageal cancer. J Gastrointest Surg 2002;6:522-6.

[16] Law S, Fok M, Chu KM, Wong J. Thoracoscopic esophagectomy for esophageal cancer. Surgery 1997;122:8-14.

[17] Minimally invasive esophagectomy for cancer Georges Decker, Willy Coosemans, Paul De Leyn a, Herbert Decaluwe', Philippe Nafteux , Dirk Van Raemdonck a, Toni Lerut -European Journal of Cardio-thoracic Surgery 35 (2009) 13-21 